\title{
Fostering Global Perspectives in Undergraduate Marketing Students- A Kazakhstani/Canadian Collaboration
}

\author{
Ina Freeman \\ Université de La Rochelle \\ Peter Knight \\ University of Wisconsin-Parkside
}

\begin{abstract}
"Globals" can cross cultural and national boundaries to effectively conduct business in most or all parts of the globe and are viewed as the business leaders of tomorrow (Bird \& Stevens, 2003). Utilizing a double-loop learning approach (Argyris, 1976), a transcontinental e-mail exchange project between undergraduate marketing students from very disparate cultures facilitated "frame-breaking" learning about global business. Although not without problems, this project appeared to clearly foster a greater cultural sensitivity and a desire to learn about global business among students. In this paper, the instructors who designed the project reflect on the value of this innovation for management educators.
\end{abstract}

\section{RÉSUMÉ}

Certaines personnes - ici appelées "Globals" - ont la capacité de traverser les frontières culturelles et nationales pour faire des affaires de par le monde. Ces "Globals " sont considérées comme les leaders du monde des affaires de demain (Bird et Stevens, 2003). Cet article rapporte les résultats d'un projet d'échange transcontinental par courrier électronique entre étudiants universitaires de premier cycle 
en marketing issus de cultures très différentes. Utilisant une approche d'apprentissage en double boucle, cet échange a permis de rompre avec les préconceptions relatives aux relations d'affaires à l'échelle internationale. Bien qu'il ne se soit pas réalisé sans difficultés, ce projet semble avoir stimulé, chez celles et ceux qui y ont participé, une plus grande sensibilité culturelle et un désir d'en apprendre davantage sur les affaires dans une perspective internationale. Les concepteurs de ce projet réfléchissent ici sur la valeur de cette innovation pour l'enseignement de la gestion.

In this paper, we discuss an innovation in the internationalization of education between two undergraduate marketing programs. Extending beyond simply fulfilling assignment requirements, the innovation encourages students to enhance their knowledge base across numerous important facets of emerging globalization including economic, political, social, cultural, religious, ethnic, and linguistic factors. It opens new doorways to students on both sides of the ocean by exposing them to a different world; for one set of students, a world for which they had no precursory knowledge by which to anticipate the reality; and for the other set of students, a world that few ever thought about.

Both authors view the traditional pedagogy in marketing in the locations of the two respective programs as highly regionalized and ethnocentric. The authors sought to jointly develop a program that would foster greater sensitivity to, awareness of, and interest in global business among their students.

This paper discusses the development, implementation, findings, and recommendations emerging from this program. The paper is written specifically for professors and instructors who are interested in introducing their students to the international environment as interpreted by students in another country without the expense of travel. This "hands-on" experience encourages discussion and ensures that neither the students nor the instructor are bored.

\section{The Problem}

Bird and Stevens (2003) define "globals" as those individuals who cross cultural and national boundaries to effectively conduct business in most or all parts of the globe. In an increasingly global business environment, business schools must increasingly be concerned with graduating students who are and are willing to become globals. The lack of international training or exposure within business school curriculum is cited in the literature as a concern (Kennedy Manzo, 2005; Haigh, 2002; Colorado Commission on Higher Education, 1994; Ray, 1990). Global/international business or marketing courses are typically non-core electives in most undergraduate business programs based on the North American model, with the exception of specialized degrees in Global or International Business. This results in many undergraduate business students not having a foundation in global business as they enter an increasingly global business environment. 
To enhance the opportunities for international business and marketing exposure, some colleges and universities bring international students into the country (Forrester, 2005). Other institutions rely on their branding by exporting and/or replicating their programs off-shore (Castle \& Kelly, 2004) as well as attracting international students to the institution's home country (Gray, Fam, \& Llanes, 2003) to enhance the international perspective of their students. Still other institutions are reaching international students via cyber universities and e-learning either as their sole focus or as a supplement to their traditional bricks and mortar institution (Croxford, 2001). In recognizing the globalization of commerce, some developing and emerging countries are modeling their programs on "Western" style education either with the assistance of a "Western" university (Oketch, 2003) or through application for membership in accreditation bodies (such as one of the institutions under examination in this paper) the New England Association of Schools and Colleges, or other institutions such as the Association to Advance Collegiate Schools of Business International.

\section{International Training and the Curriculum}

Part of the difficulty of providing a truly international experience for students may be a limited curriculum (Fairbank, Labianca, \& LeClair, 2005) resulting from a lack of international faculty exchange programs and international seminars (Ray, 1990). This supports the findings of Freeman and Knight (2004): within Canada in the locale of one of the marketing programs, $89 \%$ of faculty in business schools had received their terminal degree in North America and this percentage rose to over 97\% when faculty who gained their terminal degrees from the UK and France were added. This would seem to limit Canadian Business students' exposure to faculty who are fully conversant with the cultural and business environments of other regions of the world.

To address ethnocentrism in higher education, the Report of the Committee on International Education (Colorado Commission on Higher Education, 1994) recommends the development of consortial arrangements and increased emphasis on and funding of international education; easing of transfer credits for students to enhance international exchange programs; and increased international education partnerships with the private sector (Colorado Commission on Higher Education, 1994). However, despite these recommendations, many institutions are not responding (Kennedy Manzo, 2005). In Canada, only one university has such a full consortial arrangement (Freeman \& Knight, 2004) though many others do have exchange programs. Nonetheless, less than 1\% of Canadian University graduates experience an international exchange and only about one dollar per capita is spent on international exchange programs (Association of Universities and Colleges of Canada, 2003). Such exchange programs are also typically not available to Kazakh students. 


\section{The Study}

\section{Genesis of the Project and Development of Methodology}

The two authors initially agreed to work together on this project, inspired by a previous collaboration on the topic of international education (Freeman \& Knight, 2004). In researching exchange programs, they discovered little documentation of similar projects and thus anticipated documenting it with the view of potentially sharing the findings in a journal article upon completion to encourage and enlighten future similar collaborations. The assignment entailed electronic communication between undergraduate students in two countries, Canada and Kazakhstan, about marketing a new product in the other's country. The findings from this communication would be included in a report and submitted for course grades. Although the cultural distance between the two locales was substantial, it was felt that the two groups of students were among the more globally oriented in their respective countries and there would be enough commonalities and frames of reference to facilitate reasonable learning outcomes.

Initially the authors were in frequent e-mail contact to ensure the documentation given to the students was the same and that each author fully understood the project and their obligations and responsibilities. It must be noted that Kazakhstan is 11 hours ahead of Ontario, Canada, the location of the Canadian-based instructor. Compounding this was the lack of telephone service at the Kazakh institute after working hours and only haphazard telephone service during the day. Together, these two realities necessitated e-mail conversations. The two instructors had previously collaborated successfully in this manner. In fact, the co-authors did not actually meet face-to-face for three years (20032006) after having produced two peer-reviewed journal articles and a number of peer-reviewed conference proceedings articles.

Prior to presenting this study to either class, the authors discussed the responsibilities and obligations of themselves and the students including what limitations to place on either or both classes, the phraseology of the assignment, timelines, scheduling, correspondence levels and methodologies, scholastic expectations, and potential safety issues. Also discussed were the authors' expectations of the viability of this assignment as a learning tool. This included the following: what information needed to be collected, including restrictions on information collection such as the students' perceptions of invasion of privacy by a "foreign" instructor, different knowledge levels of students, different expectations concerning the determination of a "successful" project, and assurance that communication would be forthright and on-going. Finally, a potential survey instrument and possible analytical techniques to assess and evaluate the learning outcomes and strengths and weaknesses of the project were considered, although in many ways this was truly a process of discovery.

It was anticipated students would find marketing their chosen products or services in another country would prove surprisingly daunting based on differ- 
ences in market structure and local cultural, social, ethical, and legal/political environments, although the instructors were careful not to signal this expectation. An iterative learning process, whereby students would move gradually towards selecting a more appropriate product/service and marketing plan based on both the strengths of their home country as an exporter and the norms of the other country, was expected.

The process that made this project unique to their respective campuses and countries is the trans-continental e-mail communication between and among student groups with such highly disparate cultural and socio-economic backgrounds. Each student in Kazakhstan received e-mail addresses of a group of students from Canada and made the original contact. The project was assigned at the beginning of the term, allowing the students to complete the secondary research about the other country and decide on a proposed product for export, thus being ready to forward their questions when they received the e-mail addresses. The Kazakh students were given a one week period in which to forward their questions, with a response time of two weeks. The students in Canada received the questions and had two weeks to provide answers. Then the students in Canada forwarded their questions to their e-mail partner within a similar time period. All students were asked to copy their instructors on both the questions and the answers such that forwarding and response times could be verified.

With the description of the assignment in hand and acknowledgement of the need for different levels of instructor-student involvement, the authors introduced the topic to their respective classes.

\section{Educational Value of Teaching Innovation}

The exercise was designed with four learning objectives:

(1) Familiarization with business as it operates in another culture;

(2) Exposure to the decision process of "going international";

(3) Exposure to another country's marketing techniques and expectations; and

(4) Awakening interest in another culture including all the nuances included therein.

The assignment asked students to choose a product with which they felt comfortable and that could be marketed in the other country. This necessitated investigating the other country, its market structure, consumer tastes, social and gender roles, and legal/political environment to determine the appropriateness of their selection. The students were then given the e-mail addresses of students in the other country and asked to develop a list of questions concerning the potential introduction of their product into the other country. The responses to these questions, together with the students' individual research, would determine if further investigation into exporting the product would be beneficial. These recommendations concluded the report submitted for grading.

The instructors expected that learning for both groups of students would be "frame breaking" or "double loop" (Argyris, 1976), despite the fact that some 
students had traveled and/or were born outside Kazakhstan or Canada. Argyris (1976) proposes double loop learning theory wherein students learn to challenge or change underlying values and assumptions. Double loop theory is based upon a "theory of action" perspective outlined by Argyris and Schon (1974). This perspective examines reality from the point of view of human beings as actors. Changes in values, behavior, leadership, and helping others are all part of and informed by, the actors' theory of action. An important aspect of the theory is the distinction between an individual's espoused theory (i.e., being knowledgeable about and sensitive to cultural differences in the world around them) and their "theory-in-use" (what they actually do). Bringing these two into congruence is primary within double loop learning. Typically, interaction with others is necessary to explore the congruence between the student's perspective and reality.

\section{Evaluative Criteria for the Project}

One evaluation of the effectiveness of the innovation was the grade assigned to the papers that explored the marketplace for an existing product in the new country. The papers were graded according to the information obtained with regard to the product contemplated: that is, what factors they examined, what sources they used, and if they realistically were able to determine the potential for the success of the product in the foreign country. Much of this information necessarily came from the e-mail correspondence, particularly for the Kazakh students. This was attested to by the inclusion of the e-mails as appendices to the paper and in reading the papers. In searching the Internet, this information is not readily available. The use of e-mails indicated to the authors that the creativity, ingenuity, and willingness to share are crucial to the success of this project and to the awakening of curiosity. In addition, students were asked to share their findings with their peers through a multimedia presentation made in class. A second academic evaluation of the project was provided via a post hoc survey of the project participant's evaluation of the project, reported learning outcomes, and perceptions of strengths and weaknesses of the project.

\section{The Student Participants}

The identical assignment was given to undergraduate students in both Kazakhstan and Canada. Kazakhstan, a country in Central Asia that belongs to the Commonwealth of Independent States (CIS), is home to a number of ancient nomadic cultures, with an emerging but still largely underdeveloped economy, a history of authoritarian communist government, and pervasive social class and gender roles. In contrast, Canada is an 140 year old, G8 nation that views itself as being cosmopolitan, with one of the world's highest per capita incomes and a relatively short tradition of parliamentary democracy. Canada is a member of the World Trade Organization (WTO), whereas Kazakhstan has yet to officially join despite applying for membership in 1997. 
Kazakhstan declared independence from the collapsing Soviet Union in 1991. For many years, the domination of the USSR isolated the region from the cultural influences of the "Western World." The business school in Kazakhstan theoretically bases instruction on the American model and employs international faculty with Ph.D. credentials. Many Kazakh students come to the school knowing little of cultures and business outside the borders of the former Soviet Union. For many Kazakh students, Canada was a country neighboring the United States. The division of Canada into provinces is similar to the division of Kazakhstan into 14 provinces or oblys. But beyond that, students possessed little knowledge of Canada beyond the names of provinces or cities, and the two coastlines for shipping. Some of their misconceptions included the wealth of all Canadians, the diversity and variability of Canadian weather, and the speed of over-land transportation.

Faculty who are recruited from outside the country often find the prevalent ethnocentrism deeply seated and resistant in terms of implementing international curriculum, practices, and policies that are standard in their own countries making the transference of different standards, norms, and practices very difficult. The Kazakh university was selected for a number of reasons including the following: one of the authors was teaching in this location; this school claims to teach in English, one of the predominant languages of the Canadian students; and, the theoretical "Western" standards ensure both sets of students would have a similar understanding of academic requirements.

The Canadian university has one of the largest cohorts of international business students in Canada and places a strong emphasis on international studies in its business and other programs. As noted below nearly one third of the Canadian students providing feedback on the project were born outside of Canada.

The students in both countries were second to fourth year undergraduate students. The 36 Kazakh students were in a Business-to-Business Marketing class. In Canada, the 95 participating students were enrolled in two courses, Marketing in the Hi-Tech sector, a course for second-year Bachelor of Information Technology students, and Basic Marketing, a second-year course open to all undergraduate students. Most of the students were majoring in Economics or Industrial Design in the latter class.

Prior to the exercise, the Canadian students were perhaps more globally oriented than the norm for undergraduate business students as 30\% of the students completing the post-exercise survey (Table 1) were born outside Canada. Some Canadian students had also traveled extensively (Table 2).

The vast majority of Kazakh students were born in Kazakhstan (Table 3) and although generally isolationist in their perspectives, some of the wealthier students had also traveled extensively, albeit primarily to other CIS countries or Russia, mimicking the travels of their parents during the days of Soviet occupation. Wealth in Kazakhstan is differentially defined, with the governmental calculations influenced by the Soviet economics, which acknowledged 
Table 1

Canadian Students-Country of Birth

\begin{tabular}{lccc}
\hline Country of Birth & Frequency & Percent & Cumulative Percent \\
\hline Canada & 30 & 69.8 & 69.8 \\
Bangladesh & 1 & 2.3 & 72.1 \\
India & 1 & 2.3 & 74.4 \\
China & 3 & 7.0 & 81.4 \\
Taiwan & 1 & 2.3 & 83.7 \\
Malaysia & 1 & 2.3 & 86.0 \\
Chile & 2 & 4.7 & 90.7 \\
Sri Lanka & 1 & 2.3 & 93.0 \\
Bolivia & 1 & 2.3 & 95.3 \\
Pakistan & 1 & 2.3 & 97.7 \\
Kuwait & 1 & 2.3 & 100.0 \\
Total & 43 & 100.0 & \\
\hline
\end{tabular}

Table 2

Canadian Students-Foreign Countries Visited

\begin{tabular}{lccc}
\hline & Frequency & Percent & Cumulative Percent \\
\hline None & 3 & 7.0 & 7.0 \\
$1-3$ & 24 & 55.8 & 62.8 \\
$4-5$ & 12 & 27.9 & 90.7 \\
$7-9$ & 2 & 4.7 & 95.3 \\
10 or more & 2 & 4.7 & 100.0 \\
Total & 43 & 100.0 & \\
\hline
\end{tabular}

"under-provisioning" but not poverty until 1991. Placing defining sums on income in Kazakhstan is difficult. The middle class is gradually emerging in Kazakhstan leaving any averaging of income skewed by the wages of medical doctors working in governmental hospitals collecting less than $\$ 400$ a month and businessmen officially drawing a six figure salary, not including bonuses, perks, and gratuities. However, the wealth or poverty of the students is readily observed by the number of students (approximately one third of all business school students) who pay for their education by becoming indentured to the university for periods of one to five years following graduation. Other indicators of relative wealth and poverty include the clothing worn by the students (who are, as a group, extremely fashion conscious) and their vehicles. The students who are poor do not drive and do not have large wardrobes, with many students' wardrobes comprising of one pair of jeans and one pair of dress slacks interchanged with two to five tops. The students who are of moderate income have larger wardrobes including many fashion house knockoffs made in China or Korea and drive "beater" (i.e., old and in disrepair) cars, regularly used as 
"two finger" taxis (i.e., unlicensed private cars that are hailed by holding the index and middle finger outward toward the street) to earn gas money. The students who would be considered wealthy wear designer knockoff clothing made in Kazakhstan or Russia and drive vehicles of recent vintage. A small percentage of these students do not need extra money, but even the majority of these students use their vehicles as occasional "two finger" taxis and work in their parent's business.

Table 3

Kazakh Students - Country of Birth

\begin{tabular}{lccc}
\hline Country of Birth & Frequency & Percent & Cumulative Percent \\
\hline China & 1 & 3.7 & 3.7 \\
Kazakhstan & 23 & 85.2 & 88.9 \\
Tajikistan & 1 & 3.7 & 92.6 \\
Russia & 1 & 3.7 & 96.3 \\
Turkmenistan & 1 & 3.7 & 100.0 \\
Total & 27 & 100.0 & \\
\hline
\end{tabular}

Table 4

Kazakh Student - Foreign Countries Visited

\begin{tabular}{cccc}
\hline Foreign Countries Visited & Frequency & Percent & Cumulative Percent \\
\hline No answer & 1 & 3.7 & 3.7 \\
$1-2$ & 4 & 14.8 & 18.5 \\
$3-5$ & 12 & 44.4 & 63.0 \\
$6-9$ & 7 & 25.9 & 88.9 \\
More than 10 & 3 & 11.1 & 100.0 \\
Total & 27 & 100.0 & \\
\hline
\end{tabular}

\section{Unforeseen Challenges}

Unfortunately, some difficulties were encountered with the Kazakh university's e-mail system: that is, e-mails by the Kazakh students were taking up to four days to be received in Canada, with some never being received. Thus it was decided that all e-mails would be forwarded and received via the Kazakh-based instructor's personal e-mail, which is based in the United States and uses the English language and not as subject to monitoring ${ }^{1}$. This substantially reduced the delay and ensured the delivery of the e-mails. When Canadian e-mails were received in Kazakhstan, the e-mail was forwarded electronically and a printed copy was given to the student.

Due to the Kazakh students' unfamiliarity with using the Internet and academic journals for academic work, they were given some tools to assist them in 
their secondary literature review. One such tool was the Country Notebook website (http://highered.mcgraw-hill.com/sites/0072833718/student_view0/country_ notebook.html) which was referred to as a catalyst for students in determining what information would be pertinent for inquiry about a marketplace for their product. The instructor also developed a list of web sites that would assist the students, including the Central Intelligence Agency's (CIA) World Factbook (http:// www.cia.gov/cia/publications/factbook); the United Nations (UN) website (http:// www.un.org) which has both an English and a Russian section; the Government of Canada website (http://www.canada.gc.ca) which has multiple sites useful for contemplating importing and structuring a business in Canada; the Chamber of Commerce for Canada (http://www.chamber.ca); and The Economist Intelligence Unit (http://www.eiu.com). If the students were contemplating specific products or specific provinces, the instructor pointed out other websites that would be of initial assistance such as the provincial government websites and provincial associations. The instructor in Kazakhstan is also a Canadian citizen and was used as a resource by numerous students. Similarities were drawn between the students and business attempting to get information, utilizing the instructor as a resource or agents. For the students in Kazakhstan, the university library has a very poor and dated selection of books and limited on-line access to academic journals, necessitating the use of the Internet as the primary source of current and reliable information. For many Kazakh students, this was the first time they were required to pursue secondary sources of literature, necessitating specifically designed assistance for the students in determining the veracity and authenticity of websites.

The instructor in Canada provided few resources to his students other than the Kazakh school's website in an effort to encourage students to use their Kazakh counterparts as a primary resource in information search. Most of the Canadian students had developed proficiency with on-line research since their early days in high school and could have quite readily gathered a large portion of the basic information required for the assignment through Internet research alone. It was the opinion of the Canadian-based instructor that only through dyadic communication with the Kazakh students would they be able to truly comprehend both the surprising commonalities and differences between themselves and the Kazakh students and their respective environments. It was therefore important for the Canadian-based instructor to review content of outgoing e-mails to the Kazakh students to ensure that these students were being fully utilized as a resource.

\section{Resolving Challenges}

The originating challenge - the lack of international training for commerce students - was addressed by this innovative approach in a number of different ways. First, the students from Kazakhstan had to address some of their concerns about speaking with "foreigners." This was partially allayed by the fact that their instructor was from Canada and by the time of the assignment, they had 
found a comfort level with her. It was also allayed by the fact that the Canadian students were welcoming and friendly, and willing to participate in this type of exercise. Concomitant with this was the Kazakh students' mistrust of countries that are not either CIS or Soviet. The primary informational linkage for these students has been Russia and although they have learned to speak English, their belief in the Russian press about "the West" was difficult to overcome. They found it hard to believe the contents of the material on either the CIA Fact Book website or The Economist website because both originated from the "US government," and is believed to be propaganda, not fact.

The second challenge for the students from Kazakhstan is the identification of their country as Muslim and the fear of rejection. This fear stemmed from negative news releases and impressions following 9-11 without the contrasting reports of tolerance, acceptance, and understanding that the violence was the result of terrorists. Again, the Canadian born Kazakh-based instructor spoke frequently of the unity against terrorism and the acceptance of differences within Canada.

A third challenge for the students from Kazakhstan was the lack of available information that was not web based. The university has few texts and no current journals outside of the limited subscription to the EBSCO database. The country has no applied copyright laws and texts are routinely photocopied and resold by the university bookstore for less than the text, resulting in publishers being reluctant to sell books to the university. The university Internet system does not operate well or efficiently and at times does not operate at all. The system is disconnected at 11:00 p.m. and not accessible again until 7:00 a.m. There are few computers for the students to use and the Internet connection between the university and the telecommunication line is copper resulting in failed connections and download times for a web page in excess of 10 minutes during the day when most students are using the Internet at the university. The cost of computers is high as they are taxed upon entry into the country making the purchase of a computer frequently only affordable by the wealthy. Although many of the students at this university are wealthy by Kazakh standards, others are poor and do not have a personal home computer, making the use of the Internet at the university essential.

The fourth challenge was the very relaxed attitude of Kazakh students towards completing their course assignments. Although these students are given timelines and deadlines, the university does not enforce them. If a student produces the assignments at any time prior to the final grade submission to the Registrar, the instructor is obliged to mark the assignments; this practice that allows the students to produce assignments on the day of the final exams without penalty.

The primary challenges for Canadian students were often the mirror image of the challenges faced by the Kazakh students. Accustomed to structured deadlines and assignments, Canadian students were sometimes frustrated by what they perceived as a lack of responsiveness by the Kazakhs. Although 
the perception of the assignment and the urgency of the deadlines may have differed between Kazakh and Canadian students to some extent, Canadian students came to realize slowly of the cultural and infrastructure barriers that the Kazakhs faced. This revelation alone was rather startling to the Canadians and was a reality to which they gradually adapted.

Another challenge for the Canadian students arose from the fact that the Kazakhs did not seem to be as aware of Canada and North American life and products as first thought. This often required rethinking and reflection on the Canadian students' part to try and explain the true value proposition in their products and services chosen for the Kazakhs.

In general, however, based on review of their correspondence, there seemed to be acceptance of differences amongst the Canadian students.

\section{Assessing the Innovation's Effectiveness for Students}

In assessing the innovation's effectiveness, the authors evaluated the achievement of each of the four aforementioned goals. It must be noted that the information necessary to answer these four goals is primarily the result of the e-mail exchange, especially for the Canadian students examining Kazakhstan. Although there is some literature concerning business in Kazakhstan, much of the English literature is written by the government (giving it questionable veracity) or is written in Russian. Also, free enterprise is a relatively new concept in Kazakhstan and information is scarce or politically driven. Marketing is just beginning to make inroads and is not well understood within Kazakhstan. For the Kazakh students, there is some literature concerning the operation of business outside of Kazakhstan including globalization, but many of the databases holding these academic articles are not available in their university.

The first goal, the student's familiarization with the operations of business in another culture, was achieved for both the Kazakh and Canadian students with resounding success. The Kazakh students' previous perceptions that business operated everywhere under the same practices as in Kazakhstan, was totally debased and replaced. Many had difficulty in fathoming how business could operate without bribes and graft (Kazakhstan ranks very low on the World Bank's corruption index), but were anxious to discover how. This curiosity in itself was rewarding and for the instructor in Kazakhstan the most rewarding finding of the study was the understanding that business does not have to include corruption. The Canadian students' learning experience was the mirror image, potentially enhancing the potential of the students to work in international businesses.

The second goal of exposure to the decision to go global for the Kazakh students began as a difficult goal because there is so little knowledge of the requirements of business, even in the business environment. Many of the students were completely unaware of the existence of laws, regulations, and policies and were unable to understand why the world did not accept Kazakh products as 
Russia did. Laws, regulations, and policies were seen as obstacles to circumvent rather than with which to comply, leading one to begin to understand why so few exports come from Kazakhstan. This might be attributable to the relative age of their marketplace. The students in Canada experienced far less difficulty with this goal, although they came to the understanding of business operations in developing economy was a hard won battle.

For example, a common product proposed for export to Canada by Kazakh students was horse (kumys) and camel (schubat) milk. They were dismayed to discover that over-land shipment time from Kazakhstan was considerably longer than the freshness of the product could be guaranteed. The Kazakh students were incredulous to learn that their claims of medicinal properties of these products could not be made unless proven by someone other than their grandmothers. Further, the fact that kumys is an alcoholic drink and must be labeled as such was a revelation to them. As for the potential popularity of these products, debate remained. However, this allowed a window into a different cultural perception to that they had previously been exposed, and for some students it initiated a search into different cultures.

The third goal of exposure to another country's marketing techniques and expectations was achieved for the Kazakh students, albeit at a superficial level. Marketing in Kazakhstan is in its infancy and is the domain of existing international companies. As marketing develops in Kazakhstan, students will better be able to understand differences and similarities. However, this project exposed students to marketing and the understanding of unique characteristics within different marketplaces and marketspaces. The Canadian students' exposure resulted in understanding the importance of marketing within a society and not imposed on a society.

Through sharing their findings in their presentations, Canadian students began to understand the intricacies and barriers present in exporting to an emerging economy such as Kazakhstan. One group considered exporting premium priced composite hockey sticks as they imagined the love of hockey permeated all CIS countries. This group was dismayed to find that there was only one small patch of artificial ice in the student's city, and had not considered the limitation of disposable income of most citizens in being able to purchase such a product, the existence of complex tariffs, and a need to perhaps bribe local distributors. Another group who suggested low cost, lightweight recreational watercraft was shocked to find that the local river was so polluted that no one would ever consider boating on it for recreational purposes. Groups suggesting food products for export were surprised to learn of the differences in local tastes and staple foods.

Another group considered an Emergency Response System. This product did seem to possess some merit for export but students were told by their Kazakh contact that roving camels could sometimes tie up traffic for hours offsetting any advantages that the technology itself could provide. In the case of police response, police could not always be trusted to act appropriately, and their 
actions were complicated by bribery. Alarm systems were also suggested as a product for export; however, beyond the installation costs that were out of the range for most Kazakhs, there again were questions from the Kazakh students as to the value of even having a rapid police response.

Despite these barriers, Canadian students viewed some Canadian products and services as showing some realistic signs of potential for export (Tables 5 and 6). These products and services included business software and consulting, construction and architectural consulting, Internet infrastructure development, and joint ventures in beer and food production. Even after all of the unforeseen intricacies discovered about international trade with Kazakhstan had been considered (Table 6), these products and services were plausible. No significant differences in the perceptions of male versus female students or students born inside and outside of Canada were calculated regarding export opportunities available in Kazakhstan (Tables 5 and 6).

Table 5

Canadian Students - Does Kazakhstan provide many business opportunities for Canadians?

\begin{tabular}{|c|c|c|c|c|c|c|c|c|}
\hline $\mathrm{N}=43$ & $\begin{array}{l}\text { Born in } \\
\text { Canada }\end{array}$ & $\begin{array}{l}\text { Outside of } \\
\text { Canada }\end{array}$ & Total & $\begin{array}{c}\text { Chi } \\
\text { Square } \\
\text { Asymp. } \\
\text { Sig. }\end{array}$ & Male & Female & Total & $\begin{array}{c}\text { Chi } \\
\text { Square } \\
\text { Asymp. } \\
\text { Sig. }\end{array}$ \\
\hline & & & & & & & & .169 \\
\hline $\begin{array}{l}\text { Strongly } \\
\text { Disagree }\end{array}$ & 4 & 1 & 5 & & 5 & 0 & 5 & \\
\hline Disagree & 11 & 6 & 17 & & 9 & 8 & 17 & \\
\hline $\begin{array}{l}\text { Neither } \\
\text { Disagree or } \\
\text { Agree }\end{array}$ & 8 & 3 & 11 & & 6 & 5 & 11 & \\
\hline Agree & 7 & 3 & 10 & & 4 & 6 & 10 & \\
\hline Total & 30 & 13 & 43 & $\begin{array}{l}.818 \text { Not } \\
\text { sig. }\end{array}$ & 24 & 19 & 43 & $\begin{array}{c}.383 \text { Not } \\
\text { sig. }\end{array}$ \\
\hline
\end{tabular}

Over 50\% of Canadian students $(\mathrm{n}=43)$ identified learning about another culture and its impact on international trade as being a key learning outcome of the project. Learning was not restricted to evaluation of Canadian products for export to Kazakhstan. Imagine the "frame-breaking" learning that occurred when Canadian students were asked about the market for horse milk in Canada! An insightful marketer might not dismiss this idea entirely out of hand without at least doing a cursory examination of its potential as a niche health food or specialty product. After careful analysis, Kazakh jewelry, which is unique, very attractive, and relatively low cost, was one product that many students thought would provide a viable export opportunity to Canada. 
Table 6

Canadian Students - What Canadian products/services do you think offer the best potential for export to Kazakhstan?

\begin{tabular}{|c|c|c|c|c|c|c|c|c|}
\hline $\mathrm{N}=43$ & $\begin{array}{l}\text { Born in } \\
\text { Canada }\end{array}$ & $\begin{array}{l}\text { Outside } \\
\text { of Canada }\end{array}$ & Total & $\begin{array}{l}\text { Chi } \\
\text { Square } \\
\text { Asymp. } \\
\text { Sig. }\end{array}$ & Male & Female & Total & $\begin{array}{c}\text { Chi } \\
\text { Square } \\
\text { Asymp. } \\
\text { Sig. }\end{array}$ \\
\hline No response & 15 & 3 & 18 & & 11 & 7 & 18 & \\
\hline Staple foods & 4 & 3 & 7 & & 2 & 5 & 7 & \\
\hline Beer and wine & 0 & 3 & 3 & & 1 & 2 & 3 & \\
\hline Canadian jewelry & 0 & 1 & 1 & & 1 & 0 & 1 & \\
\hline Fast food chain & 1 & 2 & 3 & & 0 & 3 & 3 & \\
\hline $\begin{array}{l}\text { Water purification or } \\
\text { bottled water }\end{array}$ & 1 & 0 & 1 & & 1 & 0 & 1 & \\
\hline $\begin{array}{l}\text { Canadian clothing } \\
\text { and fashions }\end{array}$ & 2 & 0 & 2 & & 2 & 0 & 2 & \\
\hline Maple products & 1 & 0 & 1 & & 0 & 1 & 1 & \\
\hline Security products & 1 & 0 & 1 & & 0 & 1 & 1 & \\
\hline $\begin{array}{l}\text { IT products and } \\
\text { consulting }\end{array}$ & 4 & 1 & 5 & & 5 & 0 & 5 & \\
\hline $\begin{array}{l}\text { Medical technology } \\
\text { and services }\end{array}$ & 1 & 0 & 1 & & 1 & 0 & 1 & \\
\hline Total & 30 & 13 & 43 & $\begin{array}{l}.321 \\
\text { Not sig. }\end{array}$ & 24 & 19 & 43 & $\begin{array}{l}.138 \\
\text { Not sig. }\end{array}$ \\
\hline
\end{tabular}

The majority of Kazakh students $(88 \% n=26)$ were familiar with Canada and 55\% saw potential for Kazakh products. Probably the greatest learning experience for the students was that censorship, bribery, payoffs, high import and export tariffs, and corruption were not a part of life in Canada. This left many of the Kazakh students wondering how Canadians were able to do business.

The fourth goal of awakening interest was linked very closely to the first goal. For a number of Kazakh students, this was their first exposure to a western culture by a peer. This exposure shattered myths and stories perpetuated by older generations to keep their children close and at home. As a result of this exercise, the Kazakhstan-based instructor was able to interest seven students in international educational opportunities offered by the Bolashak scholarship program. Other students expressed interest in traveling outside the CIS and Russia, depending on visa permission. For students in a developing country with limited resources and knowledge, both of these steps indicate to the instructor in Kazakhstan that the project was a resounding success. The Canadian students discovered a little known area and discovered similarities and novel findings that encouraged them to visit Kazakhstan and surrounding CIS countries with both the potential of encouraging internationalization of business and the knowledge of some means of so doing. 
In Kazakhstan, many students had their fears of rejection or "losing face" in front of a "foreigner" replaced with open acceptance. The Kazakh students became aware they were accepted as individuals from Kazakhstan, nothing more and nothing less. They were able to address many of the stereotypes they had been taught which resulted in less reluctance to ask questions. They learned that although their marketplace was developing they were not dismissed, but were accepted as individuals. They also learned that their marketplace was based on primary products and that to assist their country to develop they had to look beyond what their parents had done to create the world in which they would live. Through gaining familiarity with Internet research, a foundation was laid for the Kazakh students to satisfy an increased curiosity about the business world beyond their borders. Projects such as this will enhance the future of business in Kazakhstan.

For the Canadian students there were a number of key learning outcomes .Only 16\% of students ( $\mathrm{n}=43$ ) surveyed stated they had ever, prior to the project, even heard of the Kazakh city of 1.3 million. Canadian student's' preconceptions that familiar consumer products in North America could be marketed in Kazakhstan in the same way as in Canada were shattered. They learned that average and disposable incomes were a minute fraction of those in Canada, except for perhaps $2-3 \%$ of the Kazakh population; and that rigid social classes and gender roles as well as bribery, corruption, and lawlessness existed to an extent that was well beyond the preconceptions of most students. Fully 65\% ( $n=43)$ of Canadian students surveyed indicated their perceptions of the region prior to the project were supported "only a little" or "not at all" by their project research.

Generally speaking, Kazakh and Canadian students perceived the intent and methodology of the project as enjoyable and valuable. Only 7\% of Canadian students $(\mathrm{n}=43)$ and 22\% $(\mathrm{N}=26)$ of Kazakh students stated in a post-project evaluation that they would not recommend the project to other students. In fact $68 \%(n=43)$ of the Canadian students would recommend the project to others without any reservation and those citing reservations typically cited the delays in gaining responses from the Kazakhs given the relatively short time frame provided for the project as being the primary negative factor associated with the project.

\section{Key Learning Experiences for Instructors}

Some of the problems and challenges encountered in this assignment arose because this was the first time this type of assignment had been tried in the Kazakh university. The challenge of e-mail censoring caused considerable consternation for Canadian students due to the relatively tight time frames of the assignments. Though resolved by all students sending and receiving their emails through the Kazakh-based instructor's personal Western-based e-mail, it is important to note that in subsequent assignments of this nature with students in emerging countries, additional time allowance must be considered.

Due to a number of factors including the uniqueness of this type of as- 
signment, some Kazakh students had considerable difficulty following directions and consequently did not make any attempt to contact their partner student, attempted to contact their partner student but did not receive reply and said nothing to the instructor, did not copy the instructor on their original e-mails, asked Canadian students questions about immigration (not at all related to the topic of the assignment), or simply refused to do the assignment as it was unlike other assignments and they were not prepared to step outside their comfort zone. Thus, one recommendation is that students be asked to forward all e-mails to the instructor for distribution and for a grade that will count toward their final grade. This would identify students who choose not to participate in the assignment, allowing early intervention such that their fears and/or isolationist attitudes can be addressed. The final assignment should be awarded a higher grade in the overall assessment such that all of the students dedicate the time required to complete it. The extreme individualism expressed by the students in doing assignments whenever it is convenient for them is a factor of the Kazakh university and cannot be dealt with by an individual instructor. In general, however, differences in pedagogical environments and cultures must also be addressed as a potential learning for the students. In any international exchange, whether in a pedagogical, business, or social setting, these differences must be acknowledged, negotiated, and overcome to achieve success. This project gave the students the opportunity to practice these skills in a non-threatening and supportive environment.

Other problems inherent in a developing country (e.g., the slow speed of the Internet due to the fact that the university refuses to change the copper coupling between the university and the Internet provider cable) are frustrating for the student and the instructor. But these realities exist and the exposure for both sets of students can produce incalculable benefits for their learning experiences. Isolationism that produces fear is a predominant feature of the country. As the students on both sides of the ocean discovered, isolationism is successfully addressed with patience and determination. For other students, their sense of superiority that justifies the isolation will be challenged as Kazakhstan continues to open its borders to the West. The lack of ethics that leads to corruption and bribery is also symptomatic of an emerging economy and will not change until the world demands that it changes. Unfortunately, for the students in Kazakhstan, the presence of oil in the Caspian may mean that demand may be a long time in coming.

When replicated, more flexibility in deadlines and longer time frames must be accorded to students for the project to be considered truly successful. The project itself should commence at the beginning of the semester rather than in the middle to allow enough time to address infrastructure and cultural issues in developing nations. In addition, students should be matched more effectively with students who have similar interests to optimize student interest in the assignment. Although the cultural differences and conflict of "theories in use" (Argyris \& Schon 1974) between students is often substantial in this type of project and offers an opportunity for robust double-loop learning to occur, 
better pairing of academic interests and accommodation for a differing sense of time would likely motivate students to participate with greater enthusiasm.

Overall, the innovation proved to be a highly valuable one and should not be discarded. A number of students have asked whether the project would be repeated in future sessions so that friends and peers could experience it. Additional positive experience with this project may also encourage other instructors at the Canadian instructor's school to consider similar innovations.

One aspect of this assignment that the instructor from the developing country noted is the need for tight guidelines concerning the assignment and its expectations. One student was overheard commenting that the assignment was being used to find a sponsor for immigration purposes in the developed country. Some of the students continue to write to each other due to their access to each other's e-mail addresses. Clearly there can be a number of unintended consequences when dealing with cultural exchanges between disparate cultures. Instructors developing such programs must be aware of these potential consequences.

Also important is the relationship between the two instructors, especially when situations and circumstances arise in the developing world that are infrequent in the developed world, such as the monitoring of the e-mails and the time delays this caused. If the two instructors are able to speak freely and openly about what is occurring, there is less chance for confusion and enhanced opportunity for further dialogue. The instructor in Canada has found that his preconceptions about the region were challenged almost to the degree that his students' preconceptions were and this learning experience should aid in setting realistic parameters and deadlines for the exercise.

\section{Adaptability of the Innovation}

The application of real-world experience is not new within higher education in the developed world, although the application does not often enough entail international experience. However, there are many universities and business faculties within the developing world that would be amenable to this type of program, if it were presented correctly. The question of the investigation of a marketplace in a foreign country could be made more comprehensive for an undergraduate level global business class or a graduate level class to include continuing contact throughout the semester and the development of a full marketing plan for an innovation.

\section{Suggestions for Replication}

A number of recommendations flow from this study for instructors interested in establishing a similar program. These include the following:

(a) Following this study, the instructor in Kazakhstan moved to North America and worked with a colleague in Kazakhstan. The success of the second project was very questionable, leading to the conclusion that the importance of the pairing and mind-set of the instructors supersedes the importance 
of the institution. Both instructors must share an equal commitment to the program. Instructors must discuss the assignment to ensure both classes are looking for similar information, have similar timelines, and have similar expectations regarding student effort and participation. Both instructors must demonstrate this commitment in their willingness to "work around" obstacles and challenges and engage in open and honest communication with both the students and each other;

(b) The acceptance of the program by both higher education institutions is necessary as students must have resources, such as ready access to computers, the Internet, and encouragement to participate in a similar program;

(c) The availability of the instructor for communication with students is mandatory, perhaps requiring a larger time commitment, depending upon the difficulties and challenges that are encountered during the project.

\section{Key Findings}

Although this paper documents an alternative program that allows students to learn about their international environment, there are key finding found pertaining to international relations, commerce, and communication. These include the following:

(a) International communication is difficult for a number of reasons, not the least of which is differences in languages, cultures, beliefs, and customs. However, many of these can be overcome with honesty and willingness to learn. Difficulties not as easy to overcome are differences in technologies and confining regulations that are a daily reality for those in developing countries, including censorship, poorly developed communication infrastructures, dated computer equipment that does not allow the sharing of files, and tolerance levels for practices that are different. These difficulties should be viewed as challenges and must be considered when contemplating doing business in a foreign environment. These add to the complexity of doing business in emerging markets, but these students have the advantage of having explored these challenges in this assignment;

(b) Although the authors designed four key objectives for this project, it became clear that learning extends beyond the classroom. The problems encountered by both the Canadian and the Kazakh students may be encountered in international business and trade. This project introduces the student to the types of situations that may arise in international trade and encourage them to apply their creativity in accomplishing their goals. The project encourages students to anticipate some of these problems when negotiating projects or when setting deadlines within different cultures;

(c) In accepting the four objectives, the authors expected the students to concentrate on learning the business culture. However, the instructors did not anticipate the benefits that would be experienced by all students as a result of being exposed to a foreign culture that was completely unlike theirs in terms of the importance of time; an understanding of the need for bribery to 
bring incomes to a living level; repercussions of communication monitoring and censoring; and, differing perceptions of importance. The e-mail project gave another country a human voice, encouraging students to explore foreign environments;

(d) Many of the students, in preparing information necessary for their e-mail partners, explored many aspects of exporting and importing in their own country. For the Kazakh students, this information was never anticipated previously. An additional learning exercise was to find the information about importing into their own country;

(e) Students were exposed to completely different marketplaces with many different needs as well as some unmet wants that could be met with foreign products. In this exposure, the students began to recognize the human similarities in foreign marketplaces, encouraging communication and globalization.

\section{NOTE}

1. All communication leaving the Kazakh university passes through censors who can change or stop the transmission.

\section{REFERENCES}

Argyris, C. (1976). Increasing leadership effectiveness. New York: Wiley.

Argyris, C. \& Schon, D. (1974). Theory in practice. San Francisco: JosseyBass.

Association of Universities and Colleges of Canada (2003). Higher education and university research: Empowering Canadians and their communities. Accessed on 9 February 2004 at http://www.aucc.ca/ pdf/english/reports/2003/ prebud_10_08_e.pdf.

Bird, A., \& Stevens, M. J. (2003). Towards an emergent global culture and the effects of globalization on obsolescing national cultures, Journal of International Management, 9(4), 395-407.

Castle, R. \& Kelly, D. (2004). International education: Quality assurance and standards in offshore teaching: Exemplars and problems. Quality in Higher Education, 10(1), 51-57.

Colorado Commission on Higher Education (1994). Report of the Committee on International Education. Denver C0: Higher Education Clearing House.

Croxford, L. (2001). Global university education: Some cultural considerations. Higher Education in Europe, 26(1), 53-60.

Fairbank, J. F., Labianca, G., \& LeClair, D. (2005). Three-Year Forecast. BizEd, (May/June), 46-51.

Forrester, D. (2005). Government is really going global. Times Educational Supplement, 4628 (4/8/2005), 4. 
Freeman, I. \& Knight, P. (2004). Hiring criteria of Canadian business schools-Focus on U.K. PhD graduates. Proceedings from Administrative Sciences Association of Canada 2004, Quebec, Canada.

Gray, B. J., Fam, K.S., \& Llanes, V.S. (2003). Branding universities in Asian markets. Journal of Product \& Brand Management, 12(2), 108-118.

Haigh, M.J. (2002). Internationalisation of the curriculum: Designing inclusive education for a small world. Journal of Geography in Higher Education, 26(1), 49-66.

Kennedy Manzo, K. (2005). International studies in hard sell in the U.S. Education Week 24 (4/20/2005), 1-2.

Oketch, M.O. (2003). The growth of private university education in Kenya: The promise and challenge. Peabody Journal of Education, 78(2), 18-30.

Ray, R. (1990). Internationalizing the business school curriculum. International Studies Notes 14(3), 83-84.

\section{CONTACT INFORMATION}

Ina Freeman

Assistant Professor

Université de La Rochelle

Technoforum - Présidence

23 avenue Albert Einstein

17071 La Rochelle

Cedex 9, France

E-Mail: ina.freeman@gmail.com

Telephone: 0546459114

Ina Freeman, Ph.D. teaches in the Group Sup de Co at Universite de La Rochelle, France. She has taught management and marketing on three continents. Her research interests include post-secondary education, segmenting within the marketplace, and international business. She and Peter Knight have worked on numerous international projects and articles.

Peter Knight is a Ph.D. candidate at Carleton Univesity in Ottawa, Ontario,Canada anticipating completion in 2007. He is currently a member of the Faculty of Business and Technology at the University of Wisconsin-Parkside in Kenosha, Wisconsin after having spent 2005-2007 as a member of the Faculty of Business and IT at UOIT in Oshawa, Ontario. Peter has published approximately 15 articles in peer reviewed journals and peer reviewed conference proceedings within the realms of management education, cross cultural learning, knowledge managment and electronic marketing performance evaluation. 